\title{
Трансформация труда в постсовременном мире: ресурсы интеграции этнической трудовой культуры (на примере Тувы и Калмыкии)
}

\author{
Любовь Б. Четырова \\ Самарский национальный исследовательский университет им. С. П. Королева, \\ Российская Федерация
}

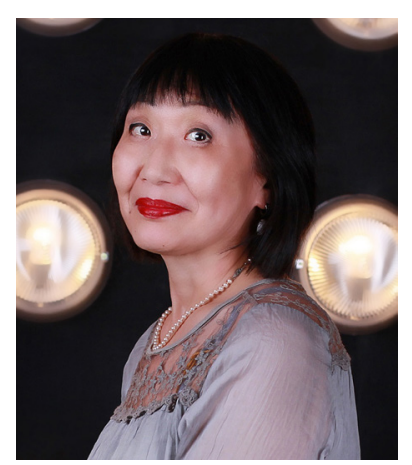

Тема труда/работы, долгое время остававшаяся в забвении, вновь обрела свою актуальность. Проблемы, возникшие вследствие роботизации, новой автоматизации, применения циирровых технологий: вытеснение (живого) производительного труда, размывание границ между трудом и досугом, появление новых форм эксплуатации работников и, как следствие, прекаризация - нуждаются в изучении. Статья посвящена рассмотрению вопроса о тех трансформациях, которые происходят с трудом и трудовой сферой в постсовременном мире, а также об условиях и возможностях интеграции носителей этнической трудовой культуры Калмыкии и Тувы в экономику постсовременного общества.

Анализ феномена труда в постсоциалистическом мире осуществляется с применением теории прекариата (Г. Стэндинг), теории цифрового (платформенного) капитализма. Для анализа российской трудовой культуры привлекается теория Д. Скотта об адаптации традиционных структур в модерном обществе, а также концепции, объясняющие неформальный сектор экономики России. Показано, как меняется модель и способы труда в циирровом (платформенном) капитализме, в условиях которого нематериальный труд (М. Лациарато) обретает формы цифрового труда, труда пользователей, создающих бесплатно различные контенты. Анализируется вопрос о неформальной экономике в России, о тех моделях труда (отходники, гаражники, распределенная мануфактура, работа в удаленных поселениях), которые стихийно вырабатываются населением, разными способами приспосабливающимися к реалиям рыночной экономики. Дается характеристика состоянию цииррового общества этнических регионов - Калмыкии и Тувы, обосновывается, что исторически сложившиеся особенности скотоводческого типа хозяйствования - отсутствие четких границ между трудом и досугом, символическая составляющая труда, навыки хозяйствования в ситуации неопределенности - могут выступать в качестве ресурсов интеграции в экономику постсовременности.

Ключевые слова: работа; труд; капитализм; постсовременное общество; информационное общество; циифровой капитализм; платформенный капитализм; этническая трудовая культура; Калмыкия; Тува

\section{Для цитирования:}

Четырова Л. Б. Трансформация труда в постсовременном мире: ресурсы интеграции этнической трудовой культуры (на примере Тувы и Калмыкии) [Электронный ресурс] // Новые исследования Тувы. 2019, № 3. URL: https:// nit.tuva.asia/nit/article/view/866 (дата обращения: дд.мм.гг.). DOI: 10.25178/nit.2019.3.7

Четырова Любовь Борисовна - доктор философских наук, профессор кафедры философии Самарского национального исследовательского университета имени академика С. П. Королева. Адрес: 443086, Россия, г. Самара, Московское шоссе, д. 34. Тел.: +7 (846) 337-99-54. Эл. адрес: chetyrova@gmail.com ORCID ID: 0000-0001-5064-8735

Chetyrova Lyubov Borisovna, Doctor of Philosophy, Professor, Department of Philosophy, Samara University. Postal address: 34 Moskovskoye shosse, 443086 Samara, Russian Federation. Tel.: +7 (846) 337-99-54. E-mail: chetyrova@gmail.com 


\title{
The transformation of work in the postmodern world: resources for integrating ethnic work culture (the case of Tuva and Kalmykia)
}

\author{
Lyubov B. Chetyrova \\ Samara University, Russian Federation
}

\begin{abstract}
Neglected for quite a while, the topic of work/labor has now become relevant again. There is a growing interest in the problems which stem from the arrival of robotics, new automation and the use of digital technologies, such as the displacement of (live) productive labor, the blurring of the boundaries between work and leisure, the emergence of new forms of exploitation of workers and, consequently, precarity. These problems deserve scholarly attention.

This article analyzes the issue of the transformations in the work sphere of the postmodern world, as well as the conditions and opportunities of integrating ethnic work culture of the Republics of Kalmykia and Tuva into the economy of postmodern society. Our analysis of the phenomenon of work in the post-Socialist world is methodologically based on the theory of precariat (G. Standing) and the theory of digital (platform) capitalism. For our study of Russian work culture, we also rely on J. Scott's theory of adapting traditional structures to modern society, as well as on concepts explaining the informal sector of the Russian economy.

The article also shows how the work/labor model and way of working is changing under digital (platform) capitalism, where immaterial labor (M. Lazzarato) takes the form of digital labor: users create various content for free.

The last section analyzes the problem of informal economy in Russia, of the models of work (such as wandering workers, garage workers, distributed manufactory, or work in remote settlements) spontaneously developed by the people adapting in various ways to the realities of market economy. It also describes the characteristics of the digital society in such ethnic regions as Kalmykia and Tuva. The article explains how some historically established features of the cattle breeding economy (lack of clear boundaries between work and leisure, the symbolic component of work, and management skills under economic uncertainty) can act as resources for integrating into postmodern economy.
\end{abstract}

Keywords: work; labor; capitalism; postmodern society; information society; digital capitalism; platform capitalism; ethnic work culture; Kalmykia; Tuva

\section{For citation:}

Chetyrova L. B. The transformation of work in the postmodern world: resources for integrating ethnic work culture (the case of Tuva and Kalmykia). The New Research of Tuva. 2019, № 3. URL: https://nit.tuva.asia/nit/article/view/866 (access date: ...). DOI: 10.25178/nit.2019.3.7

\section{Введение}

В последнее десятилетие феномен труда в культуре и те трансформации, которые происходят в области труда и общественного производства, стали объектом пристального внимания западных и отечественных исследователей. Тема труда, долгое время находившаяся на периферии исследовательского поля, вновь стала остро актуальной и на Западе, и в отечественной науке и философии. Роботизация, новая автоматизация, тотальное применение цифровых технологий изменили сложившееся в эпоху классического капитализма соотношение производства и потребления, труда и досуга, стали причинами вытеснения производительного труда из производства и, соответственно, его замещения иными формами труда. Следствием этого стала новая категоризация труда.

В статье обсуждается вопрос о трансформациях феномена труда в культуре постсовременности и возможностях интеграции этнических регионов (Тува, Калмыкия) в экономику постсовременного общества. При написании автор опирался, во-первых, на материалы обсуждений проблематики в первую очередь в англоязычной научной литературе. Анализ феномена труда в постсоциалистическом мире осуществляется с применением теории прекариата (Г. Стэндинг), теории цифрового (платформенного) капитализма. Для анализа российской трудовой культуры привлекается теория Д. Скотта об адаптации традиционных структур в модерном обществе, а также концепции, объясняющие неформальный сектор экономики России. Во-вторых, привлекаются статистические данные Росстата 2017-2018 гг., а также портала Демоскоп. 


\section{Феномен труда в постсовременном обществе}

Начавшаяся недавно четвертая промышленная революция (Шваб, 2016) привела к новой автоматизации, основанной на новом типе искусственного интеллекта, способного автоматизировать интеллектуальные способности человека. Наряду с субститутивной автоматизацией, которая замещает человека роботом, появилась супплементарная автоматизация, основанная на способности искусственного интеллекта решать нестандартные задачи (Кловайт, Ерофеева, 2019: 61-64). Оба типа автоматизации меняют отношения человека с машиной, но по-разному. Первый тип автоматизации в ряде случаев ведет к полной замене человека машиной и, соответственно, означает ликвидацию производительного (живого) труда. Последствия второго вида автоматизации более серьезны - машины забирают у людей рутинные операции, оставляя человеку лишь иконические и социальные аспекты профессии. В результате работник теряет свои компетенции, а некоторые профессии могут быть сведены к выполнению периферийных функций, оставляя человеку карикатуру на профессию (там же: 76 -77).

Новая автоматизация вкупе с цифровыми технологиями, быстро захватившими все сегменты общества, радикально поменяли природу труда, а следом за этим структуру занятого в общественном производстве населения. Согласно отчету британских исследователей из Оксфордского университета 2016 г., в результате автоматизации около 47\% рабочих мест в США будут ликвидированы. Речь идет не о работниках, занятых в промышленном производстве, большая часть которого переведена транснациональными корпорациями в азиатские страны. Сокращению подлежат высококвалифицированные работники в областях, далеких от производства. К примеру, американская компания Amazon, являющаяся крупнейшей в мире платформой для поставки услуг облачной инфраструктуры, а в последнее время робототехникой, заменяет топ-менеджеров, труд которых оценивался в 6-значных цифрах, компьютерными программами, которые оказались более эффективными ${ }^{1}$.

В оценке последствий автоматизации выделяются две основных позиции: с одной стороны, сторонники критической теории постмарксистской традиции, с другой - теоретики либерализма в разных его проявления ${ }^{2}$. Если первые дают в целом пессимистический прогноз, то вторые видят последствия новой автоматизации в позитивном свете. Наиболее ярким представителем неолиберализма является основатель экономического форума в Давосе К. Шваб (C. Schwab) (Шваб, 2016). К этой позиции примыкают исследователи, группирующиеся вокруг школы Мартина в Оксфорде (Morgan, 2014: 1-3). Первая группа исследователей довольно разнородная, но более многочисленная.

Культура Web 2.0 породила новые, прежде невиданные формы труда. Речь идет, к примеру, о неоплачиваемом труде программистов-геймеров, добровольно участвующих в совершенствовании программного обеспечения игры, благотворительном труде, сетевом обмене дарами и т. п. (Соколова, 2009: 140-143). К традиционным видам эксплуатации индивида в культуре Web 2.0 прибавилась эмоциональная и когнитивная эксплуатация просьюмеров (Бариле, 2015: 155-157).

Ярким сторонником алармической позиции является британский исследователь Г. Стэндинг (G. Standing), предостерегающий от опасности появления нового класса обездоленных - прекариата, появившегося в высокотехнологичных обществах и принявшего новый вид пауперов обществ второго и третьего мира (Standing, 2011: 1-31).

Но есть и другая позиция. В 2015 г. The Guardian опубликовала вызвавшую острую критику статью П. Мэйсона (P. Mason) «The End of Capitalism Has Began», в которой автор оптимистично провозглашает конец капитализма и наступление посткапиталистической эры ${ }^{3}$. Главными чертами нового общества он называл информационные технологии, новые способы труда и экономику sharing economy. Возражая ему, Н. Поллит (N. Pollitt) пишет, что вряд ли компании станут делить свою продукцию бесплатно. К тому же работники, потерявшие работу из-за роботов, потеряют также зарплату и не смогут покупать произведенное роботами (цит. по: McChesney, Nichols, 2016: 5-6).

H. Срничек (N. Srnicek) и А. Уильямс (A. Williams) рассматривают возможности политического решения этой проблемы. В своей книге «Изобретение будущего» формулируют альтернативу: от классиче-

\footnotetext{
${ }^{1}$ Technology at work v2.0. The Future Is Not What It Used to Ве [Электронный ресурс] // CitiVELOCITY. URL: https://www.citivelocity.com/citigps/technology-work-v2-0/ (дата обращения: 22.04.2019).

${ }^{2}$ Обзору существующих позиций и методологий исследования вопроса о труде и капитале в западной литературе посвящена статья А. Усмановой (Усманова, 2017).

${ }^{3}$ Mason P. (2015) The End of Capitalism Has Began [Электронный ресурс] // Guardian. 17 July. URL: https://www.theguardian.com/ books/2015/jul/17/postcapitalism-end-of-capitalism-begun (дата обращения: 10.04.2019).
} 
ского требования полной занятости к ориентированному на будущее требованию полной безработицы (Srnicek, Williams, 2015: 123).

Другая проблема, которая волнует Н. Срничека, - платформенный капитализм, возникший в результате появления онлайн-платформ, которые позволяют осуществить найм работника и осуществлять трудовые функции в режиме онлайн (Srnicek, 2017: 36-92).

Тема платформенного капитализма стала чрезвычайно популярной на Западе, да и в России тоже. Ей посвящена серия радиопередач Канадской телерадиовещательной компании $C B C^{1}$. Платформенный капитализм породил новый тип наемных работников - кибертариат (cybertariat). По оценкам американских экспертов, в 2015 г. каждая из трех глобальных трудовых «транзакций» будет осуществлена онлайн как часть экономики on-demand (по требованию) или crowd labor (труд толпы), использующей лишь временный найм работников (McChesney, Nichols, 2016: 71). Согласно данным Freelancers Union - организации, представляющей интересы американских фрилансеров, неформальный труд или фрилансинг уже сегодня насчитывает более трети всех наемных работников в США, что составляет 57 миллионов человек ${ }^{2}$. По прогнозам, сделанным в 2014 г., к 2018 г. онлайн-бизнес принесет 5 млрд. долларов ежегодно (Morgan, 2014: 70). В отличие от многих других, Морган дает позитивный анализ и оптимистический прогноз, указывая на такие преимущества фрилансерства, как достойная оплата труда, подвижность и свобода распоряжаться своим временем и собой (там же: 71-73). Стэндинг, например, критикует платформенный капитализм за эксплуатацию, интенсивность которой превышает прессинг, испытываемый наемными работниками в традиционных секторах экономики (Standing, 2011: 140-141).

Таким образом, в эпоху постсовременности природа труда подверглась радикальной трансформации, что оказало влияние на субъективность работника. На смену существовавшей на Западе модели институциализированного труда пришла такая, которая характерна размыванием границ между работой и иными формами активности, реализуемыми все чаще онлайн.

\section{Российские модели труда: ретроспективный взгляд}

Рассмотрим особенности российской экономики и моделей труда, сложившихся под влиянием капиталистического Запада. Насколько алармические прогнозы, артикулированные западной критической мыслью, применимы к российской экономике и российскому обществу? Действительно ли роботизация и автоматизация «грозят» российским работникам потерей рабочих мест?

На основании данных, приведенных в статистическом сборнике «Россия в цифрах. 2018», можно заключить, что есть секторы российской экономики, которые могут быть автоматизированы, однако технологическое отставание и уровень оплаты труда в России отодвигают перспективы полной автоматизации на длинную перспективу (Россия в цифрах, 2018: 91). В ближайшей перспективе работодателю в тех производствах, где есть живой труд, дешевле держать работников, чем закупать робототехнику. Хотя есть ряд отраслей, где человека заменяют современные машины. К примеру, Российские железные дороги (РЖД) за последние годы значительно снизили численность персонала, занятого в обслуживании железнодорожных путей и дистанционных сооружений.

Картина современной российской экономики довольно мозаична. Наряду с такими формами занятости, как, например, обрабатывающая или добывающая промышленность, существует так называемая неформальная экономика ${ }^{3}$. Причем то, что принято считать неформальной экономикой на Западе, фрилансерство отличается от российского понимания этого явления. Главным критерием выделения неформальной экономики у нас считается отсутствие государственной регистрации в качестве юридического лица. Сюда относятся занятые в собственном домашнем хозяйстве по производству продукции сельского, лесного хозяйства, охоты и рыболовства для продажи или обмена 4 .

В этнических регионах (регионах с коренным населением определенного этноса) доля неформального сектора в экономике довольна значительна. Так, по данным Росстата, доля занятых в неформальном секторе выросла в 2018 г. и составила 20,1\% от общей численности занятых - 14,6 млн чел. В региональ-

${ }^{1}$ Platform capitalism, digital technology and the future of work (2018) [Электронный pecypc] // CBC Radio. URL: https://www.cbc.ca/ radio/ideas/platform-capitalism-digital-technology-and-the-future-of-work-1.4297369 (дата обращения: 22.04.2019).

${ }^{2}$ https://www.freelancersunion.org/about/ (дата обращения: 29.04.2019).

${ }^{3}$ Анализ подходов к изучению российской неформальной экономики см. в статье Р. А. Анисимова (Анисимов, 2017).

${ }^{4}$ Рабочая сила, занятость и безработица - 2016 (2017) [Электронный ресурс] // Росстат. URL: http://www.gks.ru/bgd/regl/b16_61/

Main.htm (дата обращения: 10.04.2019). 
ном разрезе самая высокая неформальная занятость наблюдается в республиках Северного Кавказа: в Чечне $-64 \%$, в Дагестане - 52\%; в Ингушетии и Кабардино-Балкарии - $48 \%$. Около трети зафиксировано в Бурятии, Северной Осетии, Калмыкии. По данным Росстата, из 14,6 миллиона неформально занятых 13,7 млн чел. работают только в нем ${ }^{1}$.

Почти половина сельчан, относящихся к субъектам неформальной экономики, заняты в сельском хозяйстве, охотой и лесным хозяйством. Одна пятая из них трудится в оптовой и розничной торговле. Среди горожан более трети заняты оптовой и розничной торговлей, другими наиболее популярными видами экономической деятельности являются строительство и транспорт и связь².

Следует добавить, что реалии расходятся с данными государственной статистики. Так, по данным Центра социально-политического мониторинга Института общественных наук РАНХиГС, теневой рынок труда в 2017 г. включал 30 миллионов россиян, то есть более $40 \%$ экономически активного населения. Из них 21,7 миллионов имеют дополнительные к основному месту работу неоформленные заработки, а также те, кто получает часть зарплаты неофициально, в «конвертах». Скрытый фонд оплаты труда составил в 2017 г. около 11,4 триллиона рублей³.

Понять особенности российского неформального сектора экономики и трудовых практик, реализуемых в нем, можно лишь обратившись к истории становления советской модели труда. Есть причины, укорененные в истории становления трудовой культуры в период советской модернизации. На рубеже 1920-1930-х годов на заводы и фабрики пришел, как выразился М. Горький, «дремучий деревенский мужик» со свойственной ему «частнособственнической психологией». В написанной на солидной основе архивных материалов книге «Крепость социализма» авторы исследуют проблему мотивации труда на советском предприятии в самом начале советской модернизации (Журавлев, Мухин, 2004: 3-7).

Характерные недостаточным материальным стимулированием, механизмы мотивации труда породили латентные формы материального вознаграждения - воровство («несуны»), работу на заводском оборудовании, с использованием заводских материалов «на свой карман», использование государственного транспорта в личных целях. Стихийно сложившаяся латентная система материального вознаграждения выступала как адаптивный механизм, позволяющий работнику приспособиться к требованиям, предъявляемым работодателем - будь то завод или колхоз - в качестве которого, в конечном итоге, выступало государство.

Об этом же пишет Д. Скотт, рассматривающий в своем фундаментальном труде проблему модернизации традиционного хозяйства и культуры, в том числе адаптации работников к требованиям системы. Рассматривая советский опыт, он пишет, что «в российском сельском хозяйстве развилась неофициальная экономика, действующая на крошечных частных участках и при помощи “кражи” времени, оборудования и приспособлений из государственного сектора и поставляющая основную часть молочных продуктов, фруктов, овощей и мяса на российский стол» (Скотт, 2005: 494).

В ходе адаптации к требованиям системы у советских работников сформировались практические знания того, как и когда применять правила в конкретной ситуации. Д. Скотт называет эти адаптивные знания словом «метис», подчеркивая «тонкости применения этих правил, потому что метис наиболее ценен в контекстах, которые изменчивы, не определены (неизвестен ряд фактов) и имеют частный характер» (там же: 503).

За годы советской власти у работников сформировались адаптивные способности, благодаря которым россияне смогли пережить лихие 1990-е и приспособиться к экономическим реалиям постсоциалистического общества. Эти адаптивные способности можно рассматривать как ресурс, позволяющий индивиду действовать в ситуации неопределенности, характерной для экономики постсовременности.

Существующие сегодня формы занятости в России являются ничем иным, как результатами адаптации трудоспособного населения к меняющимся экономическим и политическим реалиям: отходничество (Отходники, 2013), хозяйствование в удаленных поселениях (Позаненко, 2018), распределенная мануфактура (Кордонский, Плюснин, 2018), «гаражная экономика» (Селеев, Павлов, 2016). По результатам проведенного Ю. Плюсниным исследования малых городов и сельских поселений, от 10-15 до

\footnotetext{
${ }^{1}$ Ситуация на рынке труда. В таблицах, графиках, диаграммах. Росстат [Электронный ресурс] // Росстат. URL: http://www.gks. ru/free_doc/new_site/population/trud/situaz.pdf (дата обращения: 10.04.2019).

${ }^{2}$ Рабочая сила, занятость и безработица - 2016 (2017) [Электронный ресурс] // Росстат. URL: http://www.gks.ru/bgd/regl/b16_61/ Main.htm (дата обращения: 10.04.2019).

${ }^{3}$ В России выросла неформальная занятость [Электронный ресурс] // Демоскоп. URL: http://www.demoscope.ru/weekly/2019/0807/rossia01.php (дата обращения: 10.04.2019).
} 
50-80\% трудоспособного населения (в основном мужчины) находят заработок на стороне. Отходничество широко развито в Калмыкии. В случае с калмыками местами отходничества являются Москва и Санкт-Петербург. По оценке Ю. Плюснина, не менее 40\% провинциальных семей обеспечивают себя за счет отходничества. Принимая во внимание, что в провинции проживают более 60\% российских семей, значит порядка 20 миллионов семей живут за счет отходничества (Отходники, 2013: 87).

\section{Возможности адаптации носителей этнической трудовой культуры к цифровому миру постсовременности}

Обратимся теперь к тому, каковы условия и возможности интеграции экономики и культуры российских этнических регионов - Калмыкии и Тувы - в постсоциалистический цифровой мир.

Этническая трудовая культура калмыков и тувинцев наряду с ресурсом приспособления, сформировавшимся в советскую эпоху, имеет укорененные в культуре кочевников ресурсы, которые могут быть использованы как для интеграции в экономику капитализма постсовременности, так и для сопротивления такому типу капитализма.

Речь идет о тех реликтах кочевой культуры, которые в том или ином виде сохранились в традиционной культуре калмыков и тувинцев, в прошлом кочевников. Д. Армстронг, различая земледельческие цивилизации и кочевые, писал, что для первых важно пространство и его освоение, а для вторых время (Armstrong, 1982: 11-12). М. Лаццарато, ссылаясь на М. Фуко, говорит о том, что капитализм осуществил захват времени жизни, тем самым устанавливая контроль над всеми ритмами человеческого существования, упорядочивая случайность. Создание рабочего класса из массы крестьян происходило скорее с помощью темпоральной секвестрации, а не политикой «огораживания» крестьянских земель ${ }^{1}$. Для создания пролетариата важнее было «огораживание» времени, создание сетки времени, которая накладывалась на жизнь рабочего, нежели «огораживание» земли. С этой точки зрения, социализм следовал логике «огораживания» времени и установления тотального контроля над жизнью. Тем не менее, сохранялся сектор экономики, где время не поддавалось разметке - это пастбищное скотоводство.

Пастбищное скотоводство, которым занимались калмыки и тувинцы в советское время и продолжают заниматься сегодня, относится к тем видам деятельности, которые отличаются высоким уровнем неопределенности. Зимние бураны, эпизоотии могут в одночасье погубить скот, а значит превратить богача в бедняка. Представления о богатстве и отношение к нему у бывших кочевников иные, чем у других народов. Привычка скотовода жить в ситуации неопределенности формирует навыки, которые применимы в любой ситуации. Культурные коды, сложившиеся у народов, ведущих скотоводческое хозяйство, наследуются и в той или иной мере сохраняются сегодня.

Далее, в таком типе хозяйства отсутствует четко размеченная граница между работой и досугом, нет внешнего дисциплинарного контроля, работник «владеет» своим временем (Ламажаа, 2018: Электр. ресурс). Подобное чувство времени также может стать ресурсом для интеграции к новым формам организации труда, возникающим в экономике постсовременности.

Кроме того, следует помнить, что труд в обществе с широко представленными неоархаическими практиками осуществляется в символическом «одеянии» и не сводится ни к простому исполнению рутинных функций, ни к «драматургическому» исполнению, каким его описал И. Гофман (Гофман, 2000: 63-84). К примеру, начало окота скота сопровождается проведением особых ритуалов, имеющих религиозную легитимацию. Для освящения вновь купленной машины, как прежде это делалось для коня, приглашается шаман или лама. Подобная символизация трудовой культуры также является важным ресурсом, облегчающим адаптацию к символическим пространствам Интернета. Выработанные в традиционной культуре навыки и умения действовать в символической реальности религиозного опыта позволяют их носителям успешно применять их в виртуальной реальности Интернета.

Следовательно, традиционные формы хозяйствования, характерные символизацией трудовых практик, формируют такие качества у работника, которые необходимы для действий в ситуации неопределенности. Все это способствует интеграции носителей этнической трудовой культуры в цифровую культуру постсовременности.

Каков же «цифровой ландшафт» в этнических регионах, какими возможностями они располагают?

\footnotetext{
${ }^{1}$ Из доклада М. Лаццарато «Отказ от труда и разрушительный досуг», сделанного на конференции «Труд и досуг в экономике и культуре будущего» 31 мая - 1 июня 2019 г. на факультете свободных искусств СПбГУ и заслушанного автором данной статьи.
} 
Для ответа на поставленный вопрос обратимся к данным мониторинга развития цифрового общества в Российской Федерации (Мониторинг ..., 2018: Электр. ресурс) и сравним показатели, характеризующие степень цифровизации в регионах и РФ в целом, рассматривая при этом этнические регионы с соседними. Для этого сопоставим Калмыкию с соседней Астраханской областью, а Туву - с Красноярским краем (см. табл. 1).

Таблица 1. Показатели, характеризующие степень цифровизации российского общества в 2018 г., в \% Tabl. 1. Indicators of the Russian society digitalization in 2018

\begin{tabular}{|c|c|c|c|c|c|c|}
\hline \multirow{2}{*}{ o } & $\begin{array}{c}\text { Показатели, характеризующие уровень } \\
\text { развития цифрового общества }\end{array}$ & РФ & Калмыкия & $\begin{array}{c}\text { Aстраханская } \\
\text { область }\end{array}$ & $\begin{array}{c}\text { Тува } \\
\text { Красноярский } \\
\text { край }\end{array}$ \\
\hline 1 & $\begin{array}{c}\text { Доля домохозяйств, имеющих доступ к } \\
\text { сети Интернет, в общем числе домашних } \\
\text { хозяйств }\end{array}$ & 76,6 & 73,8 & 82,2 & 87,4 & 72,0 \\
\hline 2 & $\begin{array}{c}\text { Численность пользователей сети Интернет } \\
\text { на 100 человек населения }\end{array}$ & 81 & 82 & 78 & 81 & 80 \\
\hline 3 & Заказ товаров и услуг через Интернет & 34,7 & 22,7 & 42,5 & 30,1 & 33,7 \\
\hline
\end{tabular}

Таблица 1 показывает, что преобладающая доля домашних хозяйств в регионах России имеет доступ к сети Интернет. При этом в Туве этот показатель выше среднего по России, а в Калмыкии, наоборот, ниже.

По показателю численности пользователей Интернета оба этнических региона опережают среднероссийский показатель, что объясняется, видимо, большим количеством детей в этнических семьях. Известно, что активными пользователями Интернета являются дети. Никого уже не удивляет, что трехлетний сельский малыш, будь то в Калмыкии или Туве, вооружившись мобильным телефоном родителей или бабушки, в поисках игр включает микрофон на поисковике и говорит: «О’кей, Гугл».

Распределение по жителям города и села показывает, что выходят в Интернет каждый день в городе $60,5 \%$, в селе - 52,5\% населения (Информационное общество: основные характеристики субъектов ... , 2018: 76).

Довольно активно используется сеть Интернет для заказа товаров и (или) услуг. Но этнические регионы уступают здесь другим и РФ в целом, что объясняется более низким уровнем доходов (табл. 1).

Активно развивается сфера получения электронных услуг онлайн - 72,2\% горожан и 51,3\% сельчан (там же).

Обратимся теперь к тому, как используется Интернет в предпринимательской и социальной сфере (см. табл. 2).

Таблица 2 показывает, что использование Интернета в предпринимательском секторе в рассматриваемых этнических регионах, преимущественно аграрных, практически не уступает соседним регионам с более диверсифицированной экономикой. Отставание обоих этнических регионов наблюдается в социальной сфере, куда относятся образование, здравоохранение, культура. Особенно отстает электронный обмен данными в социальной сфере Тувы.

Таким образом, можно оценить степень цифровизации предпринимательского и социального секторов в этнических регионах как достаточно высокую, хотя по некоторым показателям они уступают другим российским регионам.

Цифровой ландшафт этнического региона не будет полным без данных по мобильной связи. По данным мониторинга информационного общества, число мобильных телефонов на 100 домохозяйств России в 2017 г. составило в среднем 245. Доля домохозяйств, имеющих телефон, составила 99,8\%. При этом

${ }^{1}$ Показатели 1,2 взяты из «Мониторинга развития информационного общества» (Мониторинг развития информационного общества в Российской Федерации (2018) [Электронный ресурс] // Росстат. URL: http://www.gks.ru/free_doc/new_site/figure/ anketa1-4.html (дата обращения: 10.03.2019); показатели 3, 4 - из: Информационное общество: основные характеристики субъектов ..., 2018. 
только сотовый телефон имели 55,1\% домохозяйств, фиксированный и мобильный - 44,3\% ${ }^{1}$. Следует подчеркнуть важность мобильной связи, которая помимо своей основной функции обеспечивает выход в Интернет жителям удаленных сельских поселений.

Таблица 2. Интернет в предпринимательской и социальной сфере в регионах РФ, в \% в 2018 г. $^{2}$ Tabl. 2. Internet in the business and social sphere of the Russian Federation regions, \% in 2018.

\begin{tabular}{|c|c|c|c|c|c|}
\hline & Использование Интернета & Калмыкия & $\begin{array}{c}\text { Астраханская } \\
\text { область }\end{array}$ & Тува & Красноярский край \\
\hline 1. & В предпринимательском секторе & 83,6 & 87,8 & 82,3 & 89,5 \\
\hline & а) имеют вебсайты & 36,1 & 39,9 & 33,6 & 37,8 \\
\hline & $\begin{array}{c}\text { б) совершают электронный обмен } \\
\text { данными }\end{array}$ & 56,4 & 79,6 & 25,0 & 58,3 \\
\hline 2. & В социальной сфере & 68,5 & 92,8 & 70,2 & 54,3 \\
\hline & а) имеют свои вебсайты & 30,5 & 55,0 & 36,3 & 55,1 \\
\hline & б) совершают электронный обмен \\
данными & 43,7 & 86,9 & 16,4 & 53,7 \\
\hline
\end{tabular}

Таблица 3. Фиксированный и мобильный Интернет в регионах России, в \% в 2017 г. ${ }^{3}$ Chart 3. Fixed-line and mobile Internet in the Russian regions, \% in 2017

\begin{tabular}{|c|c|c|c|c|c|c|}
\hline \multirow{2}{*}{ № } & \multirow{2}{*}{ Показатели } & \multirow{2}{*}{$P \Phi$} & \multicolumn{4}{|c|}{ Российские регионы } \\
\hline & & & Калмыкия & $\begin{array}{c}\text { Астраханская } \\
\text { область }\end{array}$ & Тува & $\begin{array}{c}\text { Красноярский } \\
\text { край }\end{array}$ \\
\hline 1 & $\begin{array}{c}\text { Число абонентов фиксированного } \\
\text { широкополосного доступа в Интернет на } \\
100 \text { человек }\end{array}$ & 21,0 & 8,8 & 14,9 & 4,4 & 13,6 \\
\hline 2 & $\begin{array}{c}\text { Число абонентов мобильного } \\
\text { широкополосного доступа в Интернет на } \\
100 \text { человек }\end{array}$ & 79,9 & 67,9 & 73,1 & 45,8 & 75,6 \\
\hline
\end{tabular}

Таблица 3 демонстрирует явное отставание этнических регионов в доступе к Интернету отдельных лиц, а не домохозяйств, особенно в доступе к фиксированному Интернету. Данный недостаток восполняет мобильный широкополосный Интернет, правда, в этом отношении отставание показывает Тува. Различие показателей доступа к Интернету домохозяйств и отдельных лиц, если рассматривать этнические регионы, объясняется тем, что семьи здесь более многочисленные.

Важным ресурсом развития общества сегодня является создание принципиально новых технологий. В России удельный вес принципиально новых технологий в общем числе разработанных передовых производственных технологий на 2018 г. в целом по РФ составил 11,6\%. Показательно, что данные по Калмыкии, Туве, Астраханской области отсутствуют, а в Красноярском крае составляют 8,7\% (там же).

Наблюдаются отличия между этническими регионами и по удельному весу студентов, обучающихся по образовательным программам высшего образования - программам бакалавриата, специалитета, магистратуры, в общей численности населения в 2017 г. В целом по РФ - 2,9\%; Калмыкия - 3,0\%; Астраханская область - 2,9\%; Тува - 1,4 \%; Красноярский край $-2,7 \%$. Тува более чем в 2 раза отстает по этому показателю от Калмыкии и РФ в целом. Однако если взять такой показатель, как доля занятого населения в возрасте 25-64 лет, имеющего высшее образование, в общей численности занятого населения соответствующей возрастной группы, то в 2017 г. в РФ был показатель 35,1\%; в Калмыкии - 37,1\%; Астраханской области - 35,8 \%; Туве - 35,0 \%; Красноярском крае - 30,2 \% (там же).

\footnotetext{
${ }^{1}$ Мониторинг развития информационного общества в Российской Федерации (2018) [Электронный ресурс] // Poccтат. URL: http://www.gks.ru/free_doc/new_site/figure/anketa1-4.html (дата обращения: 10.03.2019).

${ }^{2}$ Таблица 2 составлена на основе данных из: Информационное общество: основные характеристики субъектов ..., 2018.

${ }^{3}$ Таблица 3 составлена на основе данных из источника: Мониторинг развития ...
} 
Следовательно, этнические регионы, показывая некоторое отставание по показателям цифровизации, характеризуются высокой долей лиц, имеющих высшее образование, то есть хорошим потенциалом человеческого капитала.

Если брать молодежь, то за последние десятилетия в России появилось сетевое поколение, аналогичное тому, которое сложилось на Западе. Оно имеет доступ к разнообразным информационным ресурсам, вырабатывает совершенно новые практики, правила и нормы поведения, а значит, живет уже согласно культурным кодам цифрового общества (Бродовская и др., 2019: 228-251). Важно подчеркнуть, что цифровая культура вырабатывает не только новую субъективность, но и новую телесность, новые навыки чтения и письма, использование органов чувств.

Особый интерес представляют те модели и идеи труда, которыми руководствуются молодые люди. Если взрослые еще продолжают в какой-то мере воспроизводить ценности прежней эпохи и руководствоваться прежними идеями труда, то у поколения, родившегося в эпоху радикальных экономических, политических и, в целом, культурных перемен рубежа 1980-1990-х годов, совсем иные ценности, в иерархии которых труд занимает далеко не высокие позиции. Слова Дж. Моргана, характеризующие американское поколение миллениалов, родившихся в нулевые, вполне можно отнести и к российскому поколению. Им свойствен новый тип трудового поведения, новые подходы к работе, новые установки и ожидания, предъявляемые к рабочему месту (Morgan, 2014: 14).

Доступ к Интернету в этнических регионах решает в какой-то мере проблему цифрового неравенства и снимает связанную с ней дихотомию «глобального города» и «глобального села» ${ }^{1}$. Как уже говорилось, платформы сегодня являются рынками труда, где происходит найм работников. Тем самым снимаются ограничения, накладываемые на потенциального работника, живущего в аграрном регионе, но имеющего необходимый уровень образования и, самое главное, навыки работы в сети. Это относится прежде всего к молодому поколению, телесность представителей которого уже претерпела определенные изменения и натренирована на труд онлайн. Неважно при этом, в каком регионе проживает потенциальный онлайн-работник.

Таким образом, цифровой ландшафт в рассматриваемых нами этнических регионах, где широко представлена неоархаика, в том числе и в хозяйственной деятельности, разнообразен, что свидетельствует о том, что эти регионы не относятся к «глобальному селу», исключенному из глобального цифрового мира.

\section{Заключение}

В заключение хотелось бы сказать, что анализ труда, его «смерти» и возрождения в ином качестве в высокотехнологичном обществе, трансформацию моделей труда следует рассматривать в постсоциалистической перспективе. Зачастую российские исследователи не принимают во внимание такой важный фактор, как влияние СССР и мировой системы социализма на формирование и развитие модели труда в послевоенном мире. Опасения власть имущих на Западе, что трудящиеся массы подпадут под обаяние коммунистической идеи, побуждали их обеспечивать массы всевозможными бенефитами. Это модель трудового общества, в котором все институты определялись институтом труда. В дальнейшем эта модель изжила себя под влиянием технологического прогресса. Однако мир социализма вновь оказал влияние на глобальную экономику и, соответственно, сферу труда, но теперь уже своим крушением, итогом которого стало открытие границ.

Цифровая эпоха рождает новые вызовы, в числе которых новые формы эксплуатации и обнищания масс, которым в перспективе грозит потерять работу навсегда. Однако те тенденции, которые обнаруживаются на Западе, вряд ли в полной мере проявят себя в российском обществе. Выработанные за 70 лет социализма стратегии и тактики выживания позволят работникам сохранить свою трудовую идентичность. Носители этнической трудовой культуры обладают ресурсами, укорененными в традиционном типе хозяйствования, отличительными особенностями которого являются проницаемость границ труда и досуга, отсутствие тотального контроля над ритмами жизни, символизм трудовых практик. Сформированные в скотоводческом хозяйстве навыки трудового поведения в ситуации неопределен-

${ }^{1}$ Глобальный город является конструктом, обозначающим некоторые города, которые благодаря своим экономическим, политическим ресурсам должны быть отделены от государственной системы, так как оказывают влияние по всему миру. Благодаря Интернету они получают виртуальное присутствие и цифровое воплощение (Арора, 2019: 94-104). «Глобальное село» - конструкт, обозначающий огороженное сообщество, исключенное из глобального мира (там же: 110-111). 
ности наследуются и сохраняются в культуре неоархаики. Все это вместе с достаточно высоким уровнем образования в рассматриваемых этнических регионах позволяет заключить о возможностях интеграции носителей этнической трудовой культуры данного типа в экономику постсовременности.

\section{СПИСОК ЛИТЕРАТУРЫ}

Анисимов, Р. А. (2017) Труд в эпоху неопределенности // Социологические исследования. № 11. C. 44-52. DOI: $10.7868 / \mathrm{S} 013216251711006 \mathrm{X}$

Арора, П. (2019) Переосмысление досуговых цифровых сетей с помощью глобальных городов: метафорический взгляд // Логос. № 1. Т. 29. С. 85-129.

Бариле, Н. (2015) Брендирование «я» в эпоху эмоционального капитализма. Эксплуатация «просьюмеров» от риторики double-bind к гегемонии исповеди // Логос. № 3 (105). С. 138-161.

Бродовская, Е. В., Домбровская, А. Ю., Пырма, Р. В., Синяков, А. В., Азаров, А. А. (2019) Влияние цифровых коммуникаций на формирование профессиональной культуры российской молодежи: результаты комплексного прикладного исследования // Мониторинг общественного мнения: Экономические и социальные перемены. № 1. С. 228-251. DOI: 10.14515/monitoring.2019.1.11

Гофман, И. (2000) Представление себя другим в повседневной жизни / пер. с англ., и вступ. статья А. Д. Ковалева. М. : КАНОН-пресс-Ц ; Кучково поле. 304 с.

Журавлев, С., Мухин, М. (2004) «Крепость социализма»: Повседневность и мотивация труда на советском предприятии, 1928-1938 гг. М. : РОССПЭН. 238 с.

Информационное общество Российской Федерации. 2018 (2018): статистический сборник / М. А. Сабельникова, Г. И. Абдрахманова, Л. М. Гохберг, О. Ю. Дудорова и др. ; Росстат ; Нац. исслед. ун-т «Высшая школа экономики». М. : НИУ ВШЭ. 196 с.

Информационное общество: основные характеристики субъектов Российской Федерации: статистический сборник (2018) / М. А. Сабельникова, Г. И. Абдрахманова, Л. М. Гохберг, О. Ю. Дудорова и др.; Росстат; Нац. исслед. ун-т «Высшая школа экономики». М. : НИУ ВШЭ. 216 с.

Кловайт, Н., Ерофеева, М. (2019) Работа в эпоху разумных машин: зарождение невидимой автоматизации // Логос. № 1. Т. 29. С. 53-89.

Кордонский, С. Г., Плюснин, Ю. М. (2018) Архаические экономические институты: распределенные мануфактуры в малых городах России // Мир России. № 4. С. 6-30. DOI: 10.17323/1811-038X-2018-27-46-30

Ламажаa, Ч. К. (2018) Тувинское время и экономическая культура тувинцев [Электронный ресурс] // Новые исследования Тувы. № 2. URL: https://nit.tuva.asia/nit/article/view/768 (дата обращения: 12.07.2019). DOI: 10.25178/nit.2018.2.1

Отходники (2013) / Плюснин Ю. М. и др. М. : Новый Хронограф. 376 с.

Позаненко, А. А. (2018) «Отдельная типа республичка»: структурные особенности пространственно изолированных локальных сельских сообществ // Мир России. № 4. С. 31-55. DOI: 10.17323/1811-038X2018-27-4-31-55

Россия в цифрах. Краткий статистический сборник (2018) / Росстат. М. : АНО ИИЦ «Статистика России». 522 с.

Селеев, С. С., Павлов, А. Б. (2016) Гаражники. М. : Страна Оз. 168 с.

Скотт, Дж. (2005) Благими намерениями государства: почему и как проваливались проекты улучшения условий человеческой жизни / пер. с англ. Э. Н. Гусинского, Ю. И. Турчаниновой. М. : Университетская книга. 576 с.

Соколова, Н. Л. (2009) Популярная культура Web 2.0: к картографии современного медиаландшафта. Самара : Изд-во «Самарский университет». 204 с.

Усманова, А. (2017) Онтологии множества, капитал и цифровое будущее: заметки на полях // Шаги (Steps). № 3 (2). C. 154-167.

Шваб, К. (2016) Четвертая промышленная революция. : пер. с англ. / М. : Э. 209 с.

Armstrong, J. A. (1982) Nation before nationalism. The University of North Caroline Press. 410 p. 
McChesney, R. W., Nichols, J. (2016) People get ready: the fight against a jobless economy and a citizenless democracy. New York : Nation Books. 360 p.

Morgan, J. (2014) The future of work: attract new talent, build better leaders, and create a competitive organization. Hoboken, New Jersey : John Wiley \& Sons, Inc. 234 p.

Srnicek, N. (2017) Platform capitalism. Cambridge, UK : Polity Press. 170 p.

Srnicek, N., Williams, A. (2015) Inventing the future: postcapitalism and a world without work. Brooklyn, New York : Verso Books. 245 p.

Standing, G. (2011) The Precariat. The New Dangerous Class. London ; New York : Bloomsbury. 198 p.

Дата поступления: 04.05.2019 г.

\section{REFERENCES}

Anisimov, R. A. (2017) Trud v epokhu neopredelennosti [Labor in the uncertainty epoch]. Sociologicheskie issledovaniia, no. 11, pp. 44-52. (In Russ.) DOI: 10.7868/S013216251711006X

Arora, P. (2019) Pereosmyslenie dosugovykh tsifrovykh setei s pomosch'ju global'nykh gorodov: metaforicheskii vzgliad [Re-imagining digital leisure networks through global cities: a metaphorical journey]. Logos, no. 1, vol. 29, pp. 85-129. (In Russ.)

Barile, N. (2015) Brendirovanie «ia» v epohu emotsional'nogo kapitalizma. Ekspluatatsiia «pros'yumerov» ot ritoriki double-bind $\mathrm{k}$ gegemonii ispovedi [Branding the self in the age of emotional capitalism: The exploitation of prosumers, from the rhetoric of "double bind" to the hegemony of confession]. Logos, no. 3 (105), pp. 138-161. (In Russ.)

Brodovskaia, E. V., Dombrovskaia, A. Yu., Pyrma, R. V., Siniakov, A.V. and Azarov, A. A. (2019) Vlianie tsifrovykh kommunikatsii na formirovanie professional'noi kul'tury rossiiskoi molodezhi: rezul'taty kompleksnogo prikladnogo issledovaniia [The impact of digital communications on the formation of professional culture of Russian youth: Results of a comprehensive applied research]. Monitoring obschestvennogo mneniia: Ekonomicheskie i social'nye peremeny, no. 1, pp. 228-251. (In Russ.) DOI: 10.14515/monitoring.2019.1.11

Goffman E. (2000) Predstavlenie sebia drugim v povsednevnoi zhizni [The presentation of self in everyday life]. Moscow, KANON-press-C, Kuchkovo pole. 304 p. (In Russ.)

Informatsionnoe obschestvo Rossiiskoi federatsii. 2018 [Information society of the Russian Federation. 2018] (2018): a statistical compilation / M. A. Sabel'nikova, G. I. Abdrakhmanova, L. M. Gohberg, O. Yu. Dudorova et al. Moscow, Rosstat, Nats. issled. un-t «Vysshaia shkola ekonomiki». 196 p. (In Russ.)

Informatsionnoe obschestvo: osnovnye kharakteristiki sub'ektov Rossiiskoi federatsii [Information society: Main characteristics of the constituent entities of the Russian Federation] (2018) : a statistical compilation / M. A. Sabel'nikova, G. I. Abdrakhmanova, L. M. Gohberg, O. Yu. Dudorova et al. Moscow, Nats. issled. un-t «Vysshaia shkola ekonomiki». 216 p. (In Russ.)

Klovait, N. and Erofeeva, M. (2019) Rabota v epohu razumnykh mashin: zarozhdenie nevidimoi avtomatizatsii [Work in the age of intelligent machines: the rise of invisible automation]. Logos, no. 1, vol. 29, pp. 53-89. (In Russ.).

Kordonskii, S. G. and Pljusnin, J. M. (2018) Arhaicheskie ekonomicheskie instituty: raspredelennye manufaktury v malykh gorodakh Rossii [Archaic economic institutions: "Scattered manufactories" in Russian towns]. Mir Rossii, no. 4, pp. 6-30. (In Russ.) DOI: 10.17323/1811-038X-2018-27-4-6-30

Lamazhaa, Ch. K. (2018) "Tuvan time" and economic culture of Tuvans. The New Research of Tuva, no. 2 [on-line] Available at: https://nit.tuva.asia/nit/article/view/768 (accessed: 12.07.19). (In Russ.) DOI: 10.25178/ nit.2018.2.1

Othodniki [The wandering workers] (2013) / Pljusnin Ju. M. et al. Moscow, Novyi Hronograf. 376 p. (In Russ.)

Pozanenko, A. A. (2018) «Otdel'naia tipa respublichka»: strukturnye osobennosti prostranstvenno izolirovannykh lokal'nykh sel'skih soobshhestv ["A kinda separate little republic": Structural specifics of spatially isolated local rural communities]. Mir Rossii, no. 4, pp. 31-55. (In Russ.) DOI: 10.17323/1811-038X-2018-27-4-31-55

Seleev, S. S. and Pavlov, A. B. (2016) Garazhniki [Garage people]. Moscow, Strana Oz. 168 p. (In Russ.)

Schwab, K. (2016) Chetvertaia promyshlennaia revoliutsiia [The fourth industrial revolution]. Transl. from Engl. Moscow, E. 209 p. (In Russ.) 
Skott, J. (2005) Blagimi namereniiami gosudarstva: pochemu i kak provalivalis' proekty uluchsheniia uslovii chelovecheskoi zhizni [Seeing like a state: How certain schemes to improve the human condition have failed] / trans. from English by N. Gusinsky and Yu. I. Turchaninova. Moscow, Universitetskaia kniga. 576 p. (In Russ.)

Sokolova, N. L. (2009) Populiarnaia kul'tura Web 2.0: k kartografii sovremennogo medialandshafta [Popular culture Web 2.0: towards the cartography of the modern media-landscape]. Samara, Samarskii universitet Publ. 204 p. (In Russ.)

Usmanova, A. (2018) Ontologii mnozhestva, kapital i tsifrovoe budushhee: zametki na poliakh [Ontologies of multitude, capital and the digital future: notes on the margins]. Steps, no. 3(2), pp. 154-167. (In Russ.)

Zhuravlev, S. and Muhin M. (2004) «Krepost' socializma»: Povsednevnost' i motivatsiia truda na sovetskom predpriiatii, 1928-1938 ["The fortress of Socialism": Daily life and labor motivation in a Soviet enterprise, 19281938]. Moscow, ROSSPEN. 238 p. (In Russ.)

Armstrong, J. A. (1982) Nation before nationalism. The University of North Caroline Press. 410 p.

McChesney, R. W. and Nichols, J. (2016) People get ready: the fight against a jobless economy and a citizenless democracy. New York, Nation Books. 360 p.

Morgan, J. (2014) The future of work: attract new talent, build better leaders, and create a competitive organization. Hoboken, New Jersey, John Wiley \& Sons, Inc. 234 p.

Srnicek N. (2017) Platform capitalism. Cambridge, UK., Polity Press. 170 p.

Srnicek, N. and Williams, A. (2015) Inventing the future: postcapitalism and a world without work. Brooklyn, New York, Verso Books. 245 p.

Standing, G. (2011) The Precariat. The New Dangerous Class. London, New York, Bloomsbury. 198 p.

Submission date: 04.05.2019. 